\title{
Aspectos sedimentológicos do talude continental setentrional do Rio Grande do Norte, NE do Brasil
}

\author{
Narelle Maia de ALMEIDA ${ }^{1}$, Helenice VITAL $^{2}$ \& Patricia Pinheiro Beck EICHLER ${ }^{3}$
}

1 Programa de Pós-graduação em Geodinâmica e Geofísica, Universidade Federal do Rio Grande do Norte. Campus UFRN, 1.596, CEP 59.072-970, Natal, RN, Brasil. Instituto Federal de Educação, Ciência e Tecnologia do Rio Grande do Norte, Campus Avançado Parelhas (narellemaia@gmail.com).

2 Departamento de Geologia, Programa de Pós-graduação em Geodinâmica e Geofísica, Universidade Federal do Rio Grande do Norte. Campus UFRN, 1.596, CEP 59.072-970, Natal, RN, Brasil (helenice@geologia.ufrn.br).

3 Departamento de Geologia, Programa de Pós-graduação em Geodinâmica e Geofísica, Universidade Federal do Rio Grande do Norte. Campus UFRN, 1.596, CEP 59.072-970, Natal, RS, Brasil. UNISUL, Florianópolis, Brasil (patriciaeichler@gmail. com).

Recebido em 08/2016. Aceito para publicação em 11/2017.

Versão online publicada em 16/3/2018 (www.pesquisasemgeociencias.ufrgs.br)

\begin{abstract}
Resumo - Os taludes continentais das regiões norte e nordeste brasileira carecem de dados e conhecimento e representam um ecossistema de importância econômica e ambiental. 0 objetivo deste estudo é avaliar a sedimentologia do talude continental da Bacia Potiguar, nordeste do Brasil. As amostras foram coletadas com amostrador box-corer e foram analisadas quanto a granulometria, teor de carbonato de cálcio e teor de matéria orgânica. Análises de microscopia eletrônica de varredura e difratometria de raios $\mathrm{X}$ também foram realizadas a fim de reconhecer os constituintes sedimentares das amostras em questão. A cobertura sedimentar apresenta diminuição do tamanho de grão à medida que a profundidade aumenta e é representada por quatro fácies sedimentares: silte, silte arenosa, areia siltosa e areia com cascalho. 0 teor de carbonato de cálcio é moderado a alto (37-93,2 \%) e o teor de matéria orgânica é baixo (4,6-14,5 \%). 0 talude continental é considerado misto, pois os sedimentos são compostos por siliciclásticos e bioclásticos. Dentre os siliciclásticos destacam-se Quartzo e Argilominerais. Os minerais acessórios são Ilmenita, Zircão, Titanita, Muscovita, Biotita, Glauconita, Estaurolita, Cordierita, Siderita, Rutilo, Magnetita, Turmalina, Pirita, Monazita e Barita. Bioclásticos são representados pelos briozoários, esponjas, foraminíferos, anelídeos (tubos de poliquetas), nemátodas, moluscos e diatomáceas. A presença de minerais estáveis (Zircão, Turmalina e Rutilo) indica a contribuição dos rios Açu e Apodi através dos vales incisos e canyons submarinos na sedimentação da área de estudo.
\end{abstract}

Palavras-chave: granulometria, siliciclásticos, bioclásticos, ambientes profundos.

Abstract - SEDimentological ASPECTS OF NORTHERn CONTINENTAL SLOPE OF Rio GRANDE DO NORTE, NE OF BRAZIL. The continental slopes of north and northeast regions of Brazil lack data and knowledge and they represent an ecosystem of economic and environmental importance. The aim of this study is to assess the sedimentology of the continental slope of Potiguar Basin, NE Brazil. The samples were collected with box-corer and were analyzed for grain size, calcium carbonate content and organic matter content. Scanning electron microscopy and X-ray diffraction analysis were also conducted to know the sedimentary constituents of the samples. The sedimentary cover presents a grain size decreases as the depth increases, and it is represented by four sedimentary facies: silty, sandy silt, silty sand and sand with gravel. Calcium carbonate contents is moderated to high (37-93.2\%) and the content of organic matter is low (4.6-14.5\%). It is a mixed continental slope because the sediments are composed by siliciclastics and bioclasts. Quartz and Clay minerals are the main siliciclastics. Accessory minerals are Ilmenite, Zircon, Titanite, Muscovite, Biotite, Glauconite, Staurolite, Cordierite, Siderite, Rutile, Magnetite, Tourmaline, Pyrite, Monazite and Barite. Bioclasts are represented by bryozoans, sponges, foraminifera, annelid (Polychaeta tubes), nematodes, mollusks and diatoms. The presence of stable minerals (Zircon, Tourmaline and Rutile) indicates the contributions of Açu and Apodi rivers through their incised valleys and submarine canyons in the sedimentation of study area.

Keywords: grain size, siliciclastic, bioclastic, deep environments. 


\section{Introdução}

Sob o ponto de vista da sedimentologia, considera-se que os ambientes de águas profundas são aqueles situados abaixo do nível base das ondas de tempestade, ou seja, um patamar de profundidade abaixo do qual as ondas não interagem com o fundo. Nesse contexto, estão incluídos alguns ambientes marinhos e lacustres (d'Ávila et al., 2008). Entre os ambientes marinhos profundos, destacam-se os ambientes taludais que representam um ecossistema de importância tanto econômica como ambiental.

O talude continental é a província fisiográfica que se estende desde a quebra da plataforma até o sopé continental. Fairbridge (1966) considerou que o talude continental delimita a borda estrutural do continente, estando situado sobre a zona de transição entre a espessa crosta continental e a delgada crosta oceânica. Segundo Palma (1984) é uma encosta estreita que inclina na borda da plataforma continental até profundidades que variam regionalmente, condicionadas por diferenças no regime de sedimentação e feições estruturais específicas. A inclinação média é de $4^{\circ}$. Sua largura varia geralmente entre 20 a $100 \mathrm{~km}$, e sua profundidade entre 100 e $200 \mathrm{~m}$, para a quebra superior, e 1.400 a 3.200 m para a quebra inferior. É importante ressaltar que o relevo do talude continental geralmente é irregular, ocorrendo quebras de declividade e também canyons e vales submarinos.

A superfície dos taludes continentais é composta principalmente por sedimentos finos que são varridos das plataformas continentais por processos de transporte sedimentar. As correntes de turbidez consistem de água carregada de sedimentos sendo mais densa que a água do mar circundante. Estas correntes percorrem os taludes continentais e o assoalho oceânico, erodindo o material de fundo e escavando canyons submarinos. As mesmas desempenham um importante papel na mudança dos sedimentos de mar profundo (Erickson, 2003).

Outra importante forma de transporte sedimentar nos taludes continentais são os processos gravitacionais. Consideráveis volumes de sedimentos deslizam talude continental a baixo; constituem eventos catastróficos bem como os deslizamentos terrestres, podendo mover grandes quantidades de sedimentos em questão de horas (Stoker et al., 1998; Erickson, 2003; Schwab et al., 2007).

Estudos sedimentológicos têm como objetivo proporcionar informações sobre a distribuição do tipo de fundo de uma determinada região. Estas informações básicas têm sido demandadas constantemente em estudos ambientais (EIA/RIMA), riscos geológicos para a indústria offshore, exploração dos recursos minerais e de recursos pesqueiros (Dias, 1996). Pesquisas em águas profundas requerem embarcações apropriadas e de maior porte e recursos mais significativos o que implica em maiores dificuldades ao desenvolvimento e realização do conjunto de atividades planejadas para a pesquisa.

A plataforma continental brasileira adjacente à costa norte do Rio Grande do Norte (RN) é caracterizada como uma plataforma mista composta por uma cobertura de sedimentos siliciclásticos, carbonato-siliciclásticos e carbonáticos (Pessoa Neto, 2003; Vital et al., 2008), distribuídos nas porções interna, média e externa (Gomes \& Vital, 2010), que abriga diversos compartimentos de relevo como dunas submersas, bancos de recifes de corais, rochas praiais, e proeminentes vales incisos (Testa \& Bosence, 1998; Lima \& Vital, 2006; Schwarzer et al., 2006; Vital et al., 2008, 2010a).

Apesar do recente avanço no conhecimento da plataforma continental do Rio Grande do Norte, dados da região do talude são praticamente inexistentes. Neste sentido, este trabalho pretende minimizar esta lacuna, com o objetivo de apresentar uma visão geral da sedimentologia em uma área do talude da Bacia Potiguar, quanto à granulometria, ao teor de carbonato de cálcio, ao teor de matéria orgânica, à identificação dos minerais constituintes da porção siliciclástica e dos organismos biogênicos constituintes da porção bioclástica, correlacionando-os com o ambiente em questão.

Espera-se desta forma contribuir para o conhecimento do talude potiguar brasileiro, bem como subsidiar estudos ambientais, sobretudo aqueles a serem desenvolvidos pela indústria petrolífera.

\section{2 Área, materiais e métodos}

A área selecionada para estudo abrange nove estações sedimentológicas no talude continental superior e médio, entre as isóbatas de 100 e 1.100 m, da costa setentrional do Estado do Rio Grande do Norte, adjacente aos vales incisos Açu e Apodi, no trecho compreendido entre municípios de Guamaré e Areia Branca (Fig. 1).

\subsection{Localização da área}

0 talude continental superior da costa norte do Rio Grande do Norte é compreendido entre a zona da quebra da plataforma continental, que 
pode variar entre 40 e $65 \mathrm{~m}$, e a isóbata de $300 \mathrm{~m}$. A declividade média é $\sim 15^{\circ}$. Já no talude médio, de 300 a $1.300 \mathrm{~m}$, a declividade média é $\sim 6^{\circ}$. Estudos recentes (Almeida et al., 2015) utilizando batimetria multifeixe foram realizados na área e indicam que vários canyons submarinos incisem tal talude continental, que foram denominados de oeste para leste: Canyons Areia Branca, Mossoró, Apodi, Ponta do Mel, Porto do Mangue, Macau e Açu.

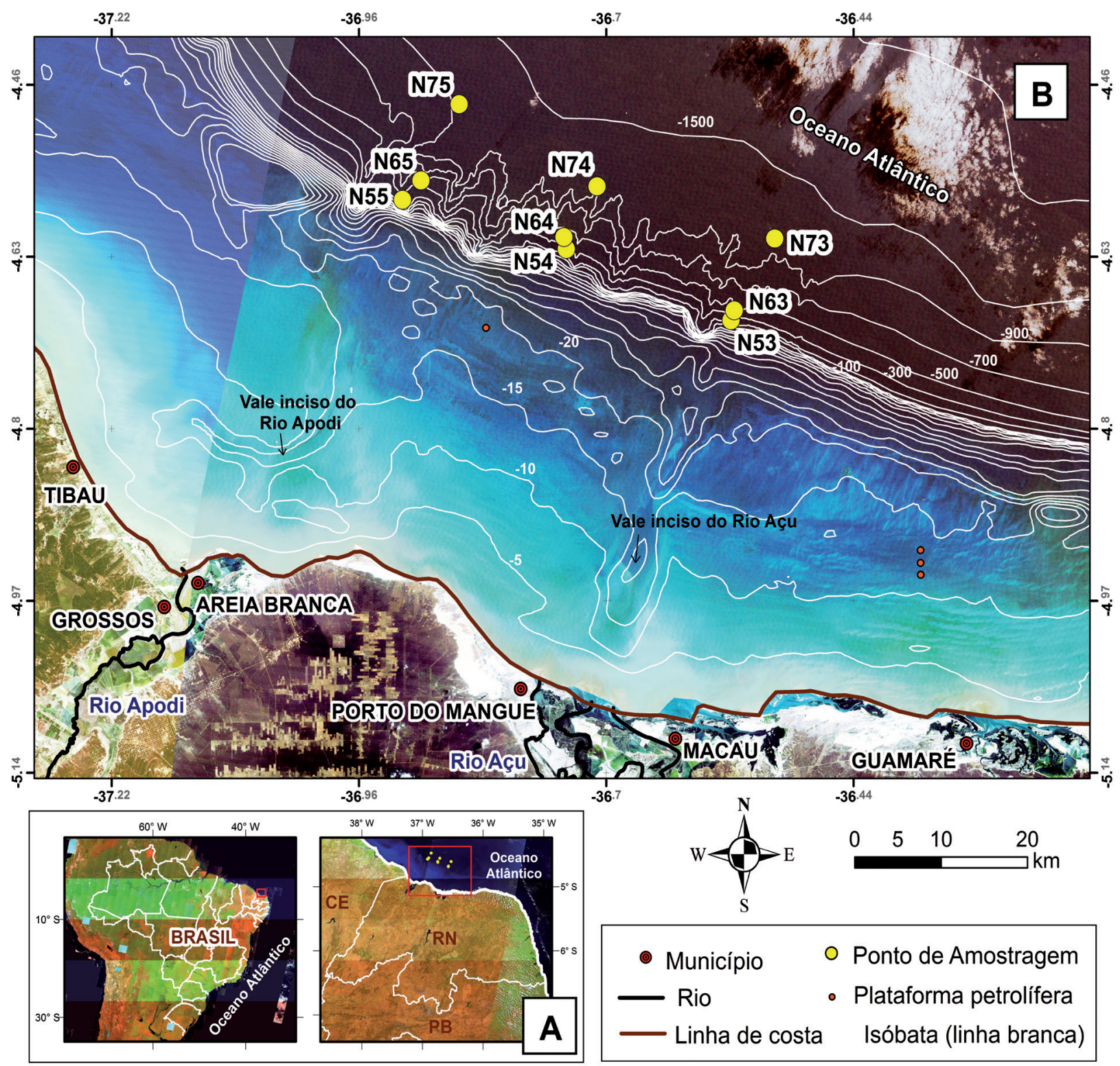

Figura 1. Localização da área de estudo. A) Talude Continental Setentrional do Rio Grande do Norte. Utilização das imagens Landsat 8, sensor OLI, resolução de 30 m, composição RGB 432; B) Localização das estações de amostragem no talude continental potiguar entre os municípios de Areia Branca e Guamaré. Isóbatas (em metros) compiladas de Gomes \& Vital (2010) e Almeida et al. (2015). Mosaico das imagens Landsat 5, sensor TM, (órbita-ponto 215-64 de 01 de setembro de 2000 e; órbita-ponto 216 63 de 29 de agosto de 2008) e Landsat 7, sensor ETM, (órbita-ponto 215-63 de 11 de junho de 2002), todas em composição RGB 321 e resolução de 30 m. Utilização do sistema de coordenadas geográficas, datum WGS 1984.

Figure 1. Location of the study area. A) Continental Slope Northern of Rio Grande do Norte. Use of Landsat 8 images, OLI sensor, 30 m resolution, RGB432; B) Location of sampling stations in Potiguar continental slope between Areia Branca and Guamaré. Isobaths (meters) compiled from Gomes \& Vital (2010) and Almeida et al. (2015). Mosaic of Landsat 5 TM (path/row 215-64 from September 1 ${ }^{\text {st }}, 2000$ and; path/row 216-63 from August 29th 2008) and Landsat 7 ETM (path/row 215-63 from June 11 ${ }^{\text {th }}$, 2002) all of them in RGB 321 with 30 m resolution. Using of Geographic Coordinate System, datum WGS 1984.

De acordo com os padrões de circulação forçada pelo vento, a área de estudo encontra-se sob influência do giro oceânico Equatorial (Mayer \& Weisberg, 1993), destacando-se a Subcorrente Norte do Brasil (SNB) e a Corrente Norte do Brasil (CNB). A SNB é uma corrente vigorosa, com núcleo atingindo $1 \mathrm{~m} / \mathrm{s}$ em profundidades de 150 a $250 \mathrm{~m}$, que transporta mais de $20 \mathrm{~Sv}$ (Silveira et al., 1994; Marin, 2009). Ao norte de $5^{\circ} \mathrm{S}$, a Corrente Sul Equatorial (CSE) faz a SNB perder a sua característica de subcorrente e se transformar na CNB (Schott et al., 1998). A SNB é uma corrente de contorno oeste 
tendendo, portanto, a acompanhar o contorno da margem continental.

Segundo Marin (2009) a SNB adentra a região já como uma corrente de contorno oeste, com núcleo entre 220 e $250 \mathrm{~m}$, nas proximidades da latitude de $11^{\text {os }}$ e com velocidades em torno de 0,8 $\mathrm{m} / \mathrm{s}$. Ainda segundo aquele autor, o núcleo da SNB se torna mais raso em seu caminho para o norte, as velocidades em superfície se tornam mais intensas devido ao aporte dos ramos da CSE e a assinatura da SNB é bastante evidente seguindo ao largo da costa em aproximadamente $5^{\circ} \mathrm{S}$. Os resultados de Marin (2009) apresentam efetivas evidencias da "transformação" da SNB em CNB ao norte do Cabo Calcanhar (RN).

A plataforma continental adjacente à área de estudo, devido às suas características geomorfológicas (muito rasa e estreita), é controlada na sua porção externa pela circulação oceânica, enquanto a porção interna encontra-se exposta à ação contínua dos ventos alísios nordeste que impulsionam a deriva litorânea e o transporte de areias costeiras de E para W-NW (Vital et al., 2010b). Encontra-se sujeita a um regime de mesomaré semi-diurno, com uma amplitude de maré de 3,3 e 1,2 m, respectivamente, durante as marés de sizígia e quadratura. As correntes predominantes são direcionadas a W-NW; a velocidade máxima da corrente offshore é em torno de $10 \mathrm{~cm} / \mathrm{s}$ em condições de maré de quadratura. Já em condições de maré de sizígia a corrente pode chegar a $40 \pm 5,9 \mathrm{~cm} / \mathrm{s}(\mathrm{Vi}-$ tal et al., 2010b).

\subsection{Materiais e métodos}

As amostras foram analisadas quanto à granulometria, teor de carbonato de cálcio, teor de matéria orgânica e composição mineralógica. A preparação das amostras para análises sedimentológicas obedeceu aos procedimentos padrões conhecidos da literatura (e.g., Shepard, 1954; McCave \& Syvitski, 1991; Loring \& Rantala, 1992).

As amostras sedimentológicas foram cedidas pela PETROBRAS - PETRÓLEO BRASILEIRO S/A. A localização das estações de coleta foi distribuída aproximadamente ao longo de quatro isóbatas, com profundidades de 150, 400 e 1.000 m conforme mostrado na figura 1.

As amostras foram coletadas com um amostrador do tipo Box-Corer e o processamento das amostras foi realizado em Laboratórios da Universidade Federal do Rio Grande do Norte (UFRN). Inicialmente as amostras foram lavadas sucessivamente com água destilada, utilizando-se centrífuga, com rotação de 4.000 rpm. Após a lavagem os sedimentos foram congelados e secos por meio de liofilizador.

\subsubsection{Análises granulométricas}

As analises granulométricas foram realizadas em um granulômetro a laser modelo 1180L, da marca CILAS, com range de 2,5 a 0,0002 mm, faixa analítica de 0,04 $\mu \mathrm{m}$ a 2,5 mm, 64 detectores, 100 classificações de tamanho de partículas, três emissões de laser e uma câmara de transformação de Fourie para análise de partículas maiores (McCave \& Syvitski, 1991). O equipamento foi programado para fornecer os dados a cada 1 phi na forma de planilhas e histogramas.

Para os cálculos estatísticos, classificação textural e construção de histogramas foi utilizado o software Sistemas de Análise Granulométrica - SAG (Dias \& Ferraz, 2004), no qual os parâmetros estatísticos e classificações texturais são baseados no método de Folk (1974) e nas classificações faciológicas de Folk (1954), Larsonneur (1977) e Dias (1996). Esta última foi simplificada por Freire et al. (1997) e posteriormente modificada por Vital et al. (2008), a qual foi empregada neste trabalho (Quadro 1).

\subsubsection{Análises do teor de carbonato de cálcio}

Para a determinação do teor de carbonato de cálcio $\left(\mathrm{CaCO}_{3}\right), 10 \mathrm{~g}$ de cada amostra foram atacados com ácido clorídrico $(\mathrm{HCl})$, diluído a 10\%. Após a eliminação completa do carbonato as amostras foram lavadas, secas em estufa e pesadas em balança digital analítica com sensibilidade de 0,0001 g. Os valores dos teores do carbonato de cálcio foram obtidos pela diferença do peso inicial (10 g) e peso final de cada amostra.

\subsubsection{Análises do teor de matéria orgânica}

Para a determinação do teor de matéria orgânica, 10 g de cada amostra foram submetidos a altas temperaturas $\left(600^{\circ} \mathrm{C}\right)$ em forno elétrico tipo mufla. Após a eliminação completa da matéria orgânica, as amostras foram secas em estufa e pesadas. Os valores dos teores da matéria orgânica foram obtidos pela diferença do peso inicial (10 g) e peso final de cada amostra.

\subsubsection{Análises mineralógicas: $M E V-E D S$ e DRX}

As análises de difratometria de raios $\mathrm{X}$ foram realizadas no Departamento de Física Teórica e 
Experimental (DFTE) da Universidade Federal do Rio Grande do Norte (UFRN). 0 método utilizado foi o de difração de raios $\mathrm{X}$ da mineralogia total (método do pó). Algumas amostras, que não se encontravam numa granulometria muito fina, fo- ram maceradas antes da preparação da lâmina. As amostras foram preparadas pela técnica de back loading, que consiste no pressionamento do pó contra a abertura de lâmina de alumínio, disposta sobre superfície lisa e firme (vidro).

Quadro 1. Classificação de sedimentos marinhos de acordo com Freire et al. (1997), modificado por Vital et al. (2008).

Chart 1. Classification of marine sediments according to Freire et al. (1997), modified by Vital et al. (2008). Facies found in the study area are in gray.

\begin{tabular}{|c|c|c|c|c|}
\hline \multirow{2}{*}{$\begin{array}{l}\text { SUBDIVISÕES } \\
\text { PRINCIPAIS }\end{array}$} & \multirow{2}{*}{$\begin{array}{c}\text { SEIXOS, GRÂNULOS, } \\
\text { COQUINAS OU } \\
\text { RODOLITOS } \\
\text { L<15\%; Md>2 mm }\end{array}$} & \multicolumn{2}{|c|}{$\begin{array}{c}\text { AREIAS } \\
\mathrm{L}<15 \% \text {; areia + lama }>50 \% \text {; } \mathrm{Md}<2 \mathrm{~mm}\end{array}$} & \multirow{2}{*}{$\begin{array}{c}\text { SEDIMENTOS } \\
\text { LAMOSOS } \\
\text { L>15\% }\end{array}$} \\
\hline & & $\begin{array}{c}15 \%<\text { superior a } 2 \mathrm{~mm} \\
<50 \%\end{array}$ & \begin{tabular}{|c|}
$\begin{array}{c}\text { superior a } 2 \mathrm{~mm} \\
<15 \%\end{array}$ \\
\end{tabular} & \\
\hline $\begin{array}{c}\text { SEDIMENTO } \\
\text { SILICICLÁSTICO } \\
\text { carbonatos }<30 \%\end{array}$ & CL1 - Cascalho siliciclástico & $\begin{array}{l}\text { AL1a - Areia siliciclástica } \\
\text { com grânulos e cascalhos }\end{array}$ & $\begin{array}{l}\text { AL1b - Areia } \\
\text { siliciclástica }\end{array}$ & $\begin{array}{l}\text { LL1 - Lama } \\
\text { terrígena }\end{array}$ \\
\hline $\begin{array}{c}\text { SEDIMENTO } \\
\text { SILICIBIOCLÁSTICO } \\
\text { carbonatos } 30 \text { a } 50 \%\end{array}$ & CL2 - Cascalho silicibioclástico & $\begin{array}{l}\text { Al2a - Areia silicibioclástica } \\
\text { com grânulos e cascalhos }\end{array}$ & $\begin{array}{c}\text { AL2b - Areia } \\
\text { silicibioclástica }\end{array}$ & $\begin{array}{l}\text { LL2 - Marga } \\
\text { arenosa }\end{array}$ \\
\hline $\begin{array}{c}\text { SEDIMENTO } \\
\text { BIOSSILICICLÁSTICO } \\
\text { carbonatos } 50 \text { a } 70 \%\end{array}$ & CB1 - Cascalho biossiliciclástico & $\begin{array}{c}\text { AB1a - Areia } \\
\text { biossiliciclástica com } \\
\text { grânulos e cascalhos }\end{array}$ & $\begin{array}{c}\text { AB1b - Areia } \\
\text { biossiliciclástica }\end{array}$ & $\begin{array}{l}\text { LB1 - Marga } \\
\text { calcárea }\end{array}$ \\
\hline $\begin{array}{c}\text { SEDIMENTO } \\
\text { BIOCLÁSTICO } \\
\text { carbonatos }>70 \% \\
\end{array}$ & CB2 - Cascalho bioclástico & $\begin{array}{l}\text { AB2a - Areia bioclástica } \\
\text { com grânulos e cascalhos }\end{array}$ & $\begin{array}{l}\mathrm{AB} 2 \mathrm{~b}-\text { Areia } \\
\text { bioclástica }\end{array}$ & $\begin{array}{l}\text { LB2 - Lama } \\
\text { calcárea }\end{array}$ \\
\hline \multicolumn{5}{|c|}{ L = Lama; Md = Mediana } \\
\hline
\end{tabular}

0 difratômetro utilizado é da marca japonesa Rigaku, modelo MiniFlex II. 0 detector utilizado é rápido, do tipo D Tex Ultra. Opera a $30 \mathrm{Kv}$ e $15 \mathrm{~mA}$ e o ânodo da fonte é de cobre com $K \alpha=0,1542$ nm e filtro de Ni. Os parâmetros utilizados para as análises foram $\theta \mathrm{i}=10^{\circ}, \theta \mathrm{f}=90 / 80$, Passo: $0,01 \mathrm{ou}$ 0,05 e Velocidade: 15 .

Os resultados foram analisados no software X'Pert HighScore Plus.

As análises de Microscopia Eletrônica de Varredura (MEV) associadas às Espectroscopia de Energia Dispersiva (EDS) foram realizadas no Laboratório de Microscopia Eletrônica de Varredura (LABMEV) do Departamento de Engenharia de Materiais (DEMat) da UFRN, onde as amostras foram adesivadas em fitas de carbono e inseridas no equipamento.

\section{Resultados e discussão}

\subsection{Parâmetros estatísticos}

Os resultados das análises granulométricas das amostras sedimentológicas do talude continental da Bacia Potiguar mostraram que, segundo a classificação de Folk (1974), os sedimentos siltosos e silto-arenosos são predominantes. Também foram reconhecidas outras duas fácies: Areia com cascalho e Areia siltosa. As curvas das frequências acumuladas de cada uma das amostras podem ser observadas na figura 2 .

Todas as amostras são compostas por duas ou mais classes granulométricas (Fig. 2). As curvas granulométricas mostram-se ligeiramente inclinadas o que indica um baixo grau de seleção dos sedimentos. Todas as amostras apresentaram valores de desvio padrão entre 1 e 2 , sendo consideradas pobremente selecionadas (Harrell, 1984).

As curvas cumulativas indicam a existência de quatro grupos de distribuição de acordo com o tamanho dos grãos (grupos A, B, C e D) (Fig. 2). 0 grupo A é caracterizado por conter sedimentos maiores que $1 \mathrm{~mm}$ ( 0 phi) sendo composto por sedimentos da fácies areia com cascalho e curtose leptocúrtica (Tab. 1; figs. 2 e 3). 0 grupo B é caracterizado por sedimentos da fácies areia siltosa e curtose mesocúrtica a leptocúrtica. Já o grupo C é composto por sedimentos da fácies silte arenoso e curtose variando de leptocúrtica a muito leptocúrtica. 0 grupo D, por sua vez, é caracterizado por materiais mais finos de granulometria silte com curtose variando de mesocúrtica a platicúrtica.

\subsubsection{Assimetria}

A assimetria é obtida pelo afastamento do diâmetro médio em relação à mediana (Inman, 1952), descrevendo se a curva é ou não simétrica. Havendo predominância nos sedimentos de partículas finas ou grossas, a assimetria pode ser consi- 
derada positiva ou negativa respectivamente.

Os valores de assimetria das amostras da área de estudo variaram entre 0,03 e 0,39 , predominando valores em torno de 0,24 e 0,34 o que revela uma tendência destes sedimentos a uma distri- buição assimétrica positivamente (44\%) e muito positivamente (44\%) (Tab. 1). Amostras de profundidades menores que $400 \mathrm{~m}$ tendem a uma distribuição fortemente assimétrica, pois apresentam valores de assimetria acima 0,30.

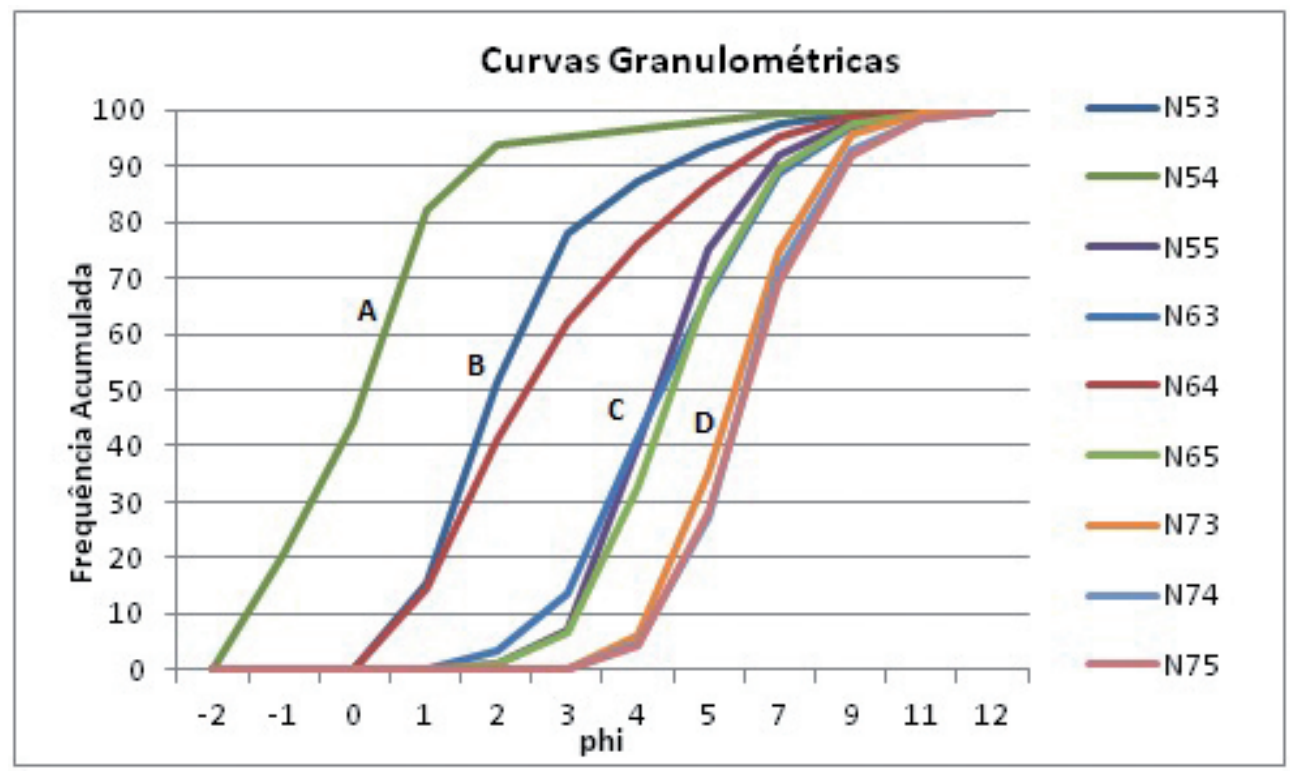

Figura 2. Curvas granulométricas dos sedimentos recentes do talude continental da Bacia Potiguar. Figure 2. Granulometric curves of Potiguar Basin recent continental slope sediments.

Tabela 1. Parâmetros estatísticos das amostras do talude continental potiguar e suas classificações segundo Folk (1974). Table 1. Statistical parameters of Potiguar Basin continental slope sediments and the classification according to Folk (1974).

\begin{tabular}{|c|c|c|c|c|c|c|c|c|c|}
\hline Amostra & $\begin{array}{c}\text { Profundidade } \\
(\mathrm{m})\end{array}$ & Mediana & Média & $\begin{array}{l}\text { Desvio } \\
\text { Padrão }\end{array}$ & $\begin{array}{l}\text { Grau de } \\
\text { seleção }\end{array}$ & Assimetria & Assimetria & Curtose & Curtose \\
\hline N53 & -140 & 1.96 & 2.20 & 1.39 & $\begin{array}{l}\text { Pobremente } \\
\text { selecionado }\end{array}$ & 0.39 & $\begin{array}{c}\text { Assimetria muito } \\
\text { positiva }\end{array}$ & 1.29 & Leptocúrtica \\
\hline N54 & -176 & 0.15 & 0.04 & 1.20 & $\begin{array}{l}\text { Pobremente } \\
\text { selecionado }\end{array}$ & 0.03 & $\begin{array}{l}\text { Aproximadamente } \\
\text { simétrica }\end{array}$ & 1.13 & Leptocúrtica \\
\hline N55 & -283 & 4.29 & 4.54 & 1.42 & $\begin{array}{l}\text { Pobremente } \\
\text { selecionado }\end{array}$ & 0.34 & $\begin{array}{l}\text { Assimetria muito } \\
\text { positiva }\end{array}$ & 1.51 & $\begin{array}{l}\text { Muito } \\
\text { leptcúrtica }\end{array}$ \\
\hline N63 & -420 & 4.33 & 4.66 & 1.68 & $\begin{array}{l}\text { Pobremente } \\
\text { selecionado }\end{array}$ & 0.30 & Assimetria positiva & 1.13 & Leptocúrtica \\
\hline N64 & -399 & 2.42 & 2.74 & 1.82 & $\begin{array}{l}\text { Pobremente } \\
\text { selecionado }\end{array}$ & 0.35 & $\begin{array}{l}\text { Assimetria muito } \\
\text { positiva }\end{array}$ & 1.02 & Mesocúrtica \\
\hline N65 & -399 & 4.49 & 4.78 & 1.54 & $\begin{array}{l}\text { Pobremente } \\
\text { selecionado }\end{array}$ & 0.33 & $\begin{array}{l}\text { Assimetria muito } \\
\text { positiva }\end{array}$ & 1.19 & Leptocúrtica \\
\hline N74 & -1000 & 6.04 & 6.24 & 1.73 & $\begin{array}{l}\text { Pobremente } \\
\text { selecionado }\end{array}$ & 0.23 & Assimetria positiva & 0.97 & Mesocúrtica \\
\hline N75 & -1003 & 6.08 & 6.29 & 1.78 & $\begin{array}{l}\text { Pobremente } \\
\text { selecionado }\end{array}$ & 0.24 & Assimetria positiva & 0.91 & Mesocúrtica \\
\hline NT73 & -1029 & 5.75 & 5.99 & 1.59 & $\begin{array}{l}\text { Pobremente } \\
\text { selecionado }\end{array}$ & 0.24 & Assimetria positiva & 0.86 & Platicúrtica \\
\hline
\end{tabular}

\subsubsection{Curtose}

De uma maneira geral, as interpretações sobre os valores de curtose dizem respeito às condições de movimentação do ambiente sedimentar. Assim curvas leptocúrticas a muito leptocúrticas indicam zonas de maior energia, enquanto que curvas platicúrticas a muito platicúrticas representam zonas de menor movimentação (Cunha, 1982).

Os sedimentos apresentam valores de curtose variando de 0,86 a 1,51, correspondendo a uma ampla faixa de classificação de suas curvas, englobando desde curvas platicúrticas até muito leptocúrticas. Verificou-se a predominância de distribuições leptocúrticas (45\%), seguidas por distribuições mesocúrticas (33\%), muito leptocúrti- 
cas (11\%) e platicúrticas (11\%).

A distribuição dos sedimentos indica que amostras mesocúrticas a platicúrticas ocorrem de maneira mais expressiva na parte norte da área estudada, refletem assim a dominância de um ambiente geológico atuante com mais baixa energia (Tab. 1; fig. 1). Os valores leptocúrticos e muito leptocúrticos representam a porção sul da área de estudo, distribuindo-se principalmente no talude continental superior, estando relacionados a sedimentos com valores de desvio padrão menores $(1,20$ a 1,54$)$ o que indica uma melhor seleção e um ambiente de maior energia.

\subsection{Distribuição das fácies texturais}

Ao longo do talude continental setentrional do Rio Grande do Norte, no trecho compreendido entre Areia Branca e Guamaré, foram reconhecidas quatro fácies sedimentares segundo a classificação de Folk (1954) (Fig. 3).

Nas porções mais rasas, destacou-se a fácies silte arenosa (33\%) nas proximidades das isóbatas de 300 e $400 \mathrm{~m}$. As fácies areia siltosa (23\%) e areia com cascalho (11\%) também foram mapeadas nas porções mais rasas da área.

Já nas porções mais profundas, destacou-se a fácies siltosa (33\%) nas proximidades da isóbata de $1.000 \mathrm{~m}$. Tal distribuição, fácies mais grossas nas regiões mais rasas e fácies mais finas em regiões mais profundas, mostra uma perfeita concordância com os mecanismos deposicionais do sistema marinho, já que fácies mais finas tendem ocupar locais de mais altas profundidades e menor energia (e.g., Moreira \& Carminatti, 2004; d'Ávila et al., 2008).

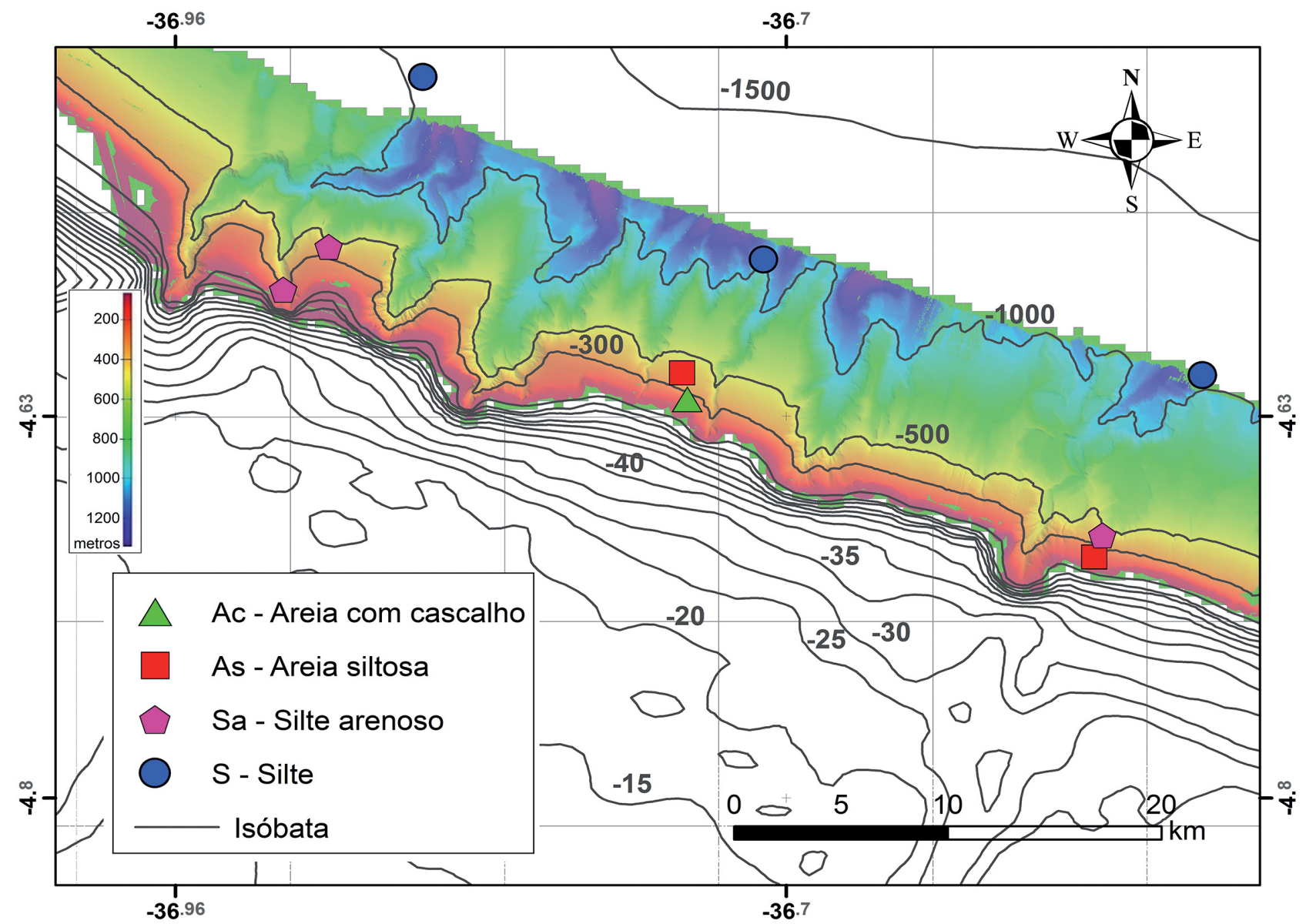

Figura 3. Distribuição das fácies sedimentares segundo a classificação de Folk (1954).

Figure 3. Distribution of sedimentary facies according to classification of Folk (1954).

Segundo a classificação de Freire et al. (1997), modificada por Vital et al. (2008) (Fig. 4; quadro 1), cinco fácies distintas foram mapeadas. Não há uma relação evidente entre a distribuição das fácies e a profundidade, pois as fácies ocorrem de maneira heterogênea. A porção leste da área, onde foram mapeadas as fácies AL2b - Areia silicibioclástica e LL2 - Marga arenosa, possui maior influência do transporte e sedimentação de sedimentos siliciclásticos que a porção oeste da área, uma vez que a porção leste é constituída por fácies silicibioclásticas e a oeste por fácies bioclásticas (Fig. 4; quadro 1). 




Figura 4. Distribuição das fácies sedimentares segundo a classificação de Dias (1996), simplificada por Freire et al. (1997) e adaptada por Vital et al. (2008).

Figure 4. Distribution of sedimentary facies according to the classification of Dias (1996), simplified by Freire et al. (1997) and adapted by Vital et al. (2008).

Os teores de carbonato de cálcio apresentaram variação entre 37 e 93,2\% o que ilustra o caráter misto (siliciclástico-carbonático) com tendência a carbonático dos sedimentos recentes do talude continental da Bacia Potiguar.

$\mathrm{Na}$ porção leste da área foram observados valores mais baixos de $\mathrm{CaCO}_{3}$ (entre 37 a 48,2\%) associados a sedimentos com granulometria silte, silte arenoso e areia siltosa (Figs. 3 e 5). Esta porção coincide exatamente com o canyon submarino do Rio Açu, sendo então considerada uma área de mais alta energia, possivelmente devido a correntes de turbidez que podem carrear sedimentos siliciclásticos, tornando o ambiente menos propício ao surgimento e preservação dos sedimentos bioclásticos devido a uma maior dificuldade na precipitação dos íons de carbonato de cálcio em suas proximidades. A área leste é caracterizada pela presença de sedimentos silicibioclásticos (Fig. 4; Quadro 1) nos quais o teor de carbonato de cálcio varia entre 30 e $50 \%$. Os teores intermediários (59,3 - 65,5\%) foram encontrados nas profundidades de 283 e 399 m, associados à granulometria silte arenoso, na porção oeste da área.
Teores elevados de carbonato de cálcio (70 $80 \%$ ) foram mapeados em águas mais profundas, da ordem de $1.000 \mathrm{~m}$, associados à granulometria silte. Entretanto, o maior teor de $\mathrm{CaCO}_{3}$ da área de estudo $(93,2 \%$, amostra N54) foi mapeado na profundidade de $176 \mathrm{~m}$ e foi classificada como areia com cascalho de acordo com a classificação de Folk (1954) ou areia bioclástica com grânulos e cascalho de acordo com a classificação de Freire et al. (1997) adaptada por Vital et al. (2008). A presença de recifes carbonáticos na borda da plataforma continental (Almeida et al., 2015) explica esses valores mais altos. Estes recifes possivelmente são a fonte de parte dos sedimentos da amostra N54, influenciando a sedimentação local, tornando-a mais grossa e carbonática na porção central da área de estudo.

A matéria orgânica nos sistemas aquáticos está sob forma de carbono dissolvido total (COD) e particulado (COP) detrítico que pode ser originada da complexa mistura de lipídios, carboidratos, proteínas, e outros compostos produzidos por organismos desses ambientes (Meyers \& Lallier-Vergés, 1999) e/ou transportada de águas mais rasas 
e continentais.

A porcentagem de matéria orgânica particulada dos sedimentos superficiais da área em estudo varia entre 4,6 e $14,5 \%$ (Fig. 6). Os menores valores de matéria orgânica particulada $(4,6$ a 6,7\%) estão geralmente associados a amostras com bai- xas percentagens em carbonatos ( 37 a $48,2 \%$ ) e foram mapeadas na porção leste o que confirma que o ambiente do canyon Açu é o ambiente de mais alta energia da área de estudo, já que a matéria orgânica tende a ser mais depositada em ambientes de baixa energia e não oxidantes.

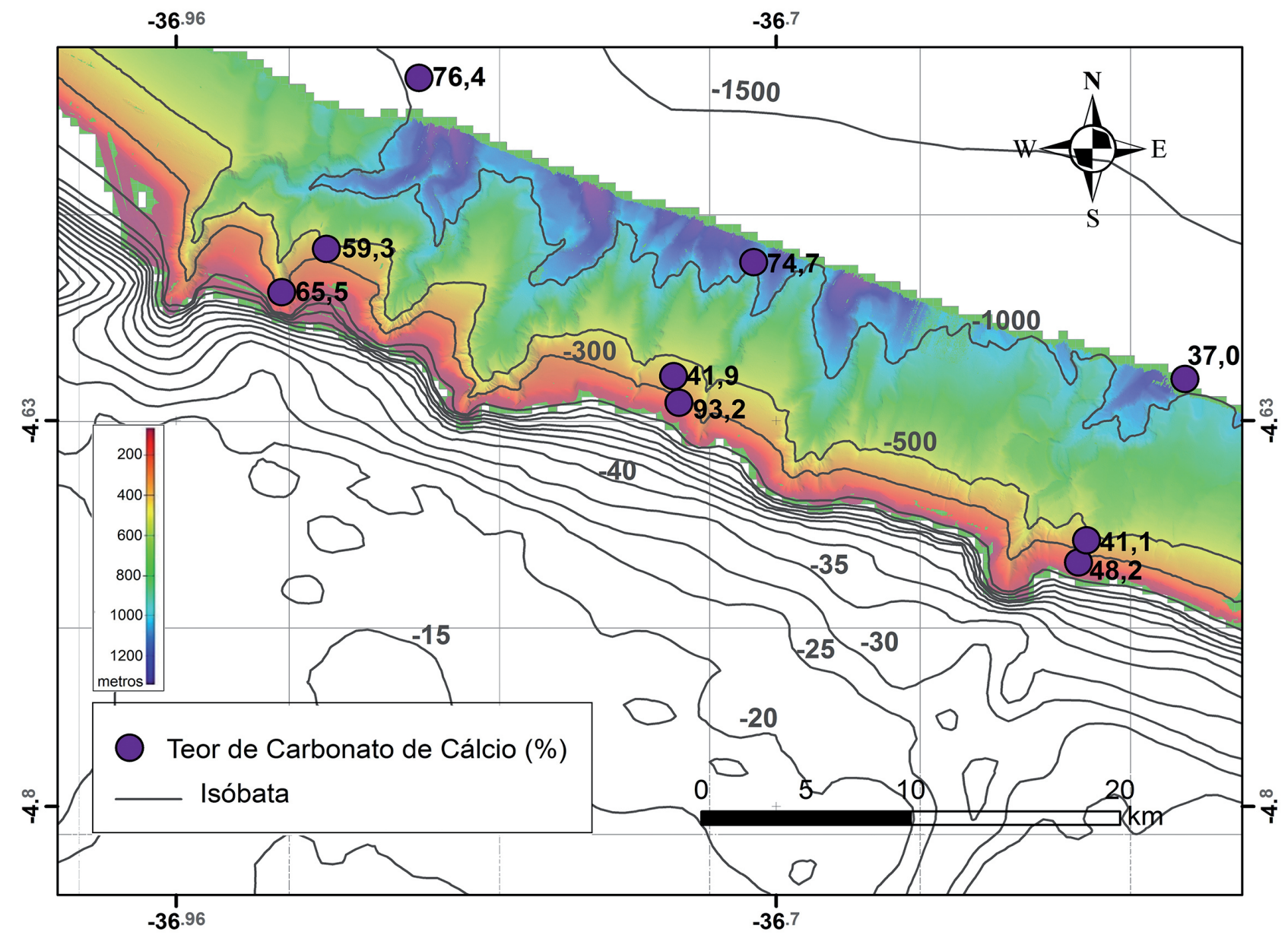

Figura 5. Distribuição do teor de carbonato de cálcio. Figure 5. Distribution of calcium carbonate content.

Teores de matéria orgânica acima de 10\% foram encontrados nas profundidades 1.000 e 1.003 $\mathrm{m}$, correspondendo a sedimentos mais finos como silte, ou seja, ambientes de mais baixa energia.

Em teoria, a matéria orgânica no talude continental alcançaria um pico de abundância, pois a taxa de deposição de detritos sílticos e argilosos é mais lenta do que a da matéria orgânica. Além disso, a matéria orgânica é acrescida rapidamente, antes que venha a sofrer oxidação. A preservação é auxiliada ainda pela profundidade moderada (Emery, 1965). Entretanto, os teores de matéria orgânica encontrados neste estudo $(4,6$ a 14,5\%) são considerados baixos em comparação aos teores acima de 30\% registrados por Borges (2012) e Abreu Neto (2012), respectivamente na plataforma da Bacia Potiguar e no talude do Ceará.

Pode-se atribuir esses baixos valores de matéria orgânica encontrados na área de estudo à atua- ção do Vórtice de Macau (VM) mapeado por Marin (2009) (Fig. 7). O VM é um meandro anticiclônico frontal centrado na longitude da cidade de Macau (RN) com cerca de $150 \mathrm{~km}$ de raio. É considerado uma resposta à inércia da SNB, na tentativa de conservar a vorticidade potencial, frente à abrupta mudança da orientação da margem continental em $5^{\circ} \mathrm{S}$. Parte da SNB segue em direção ao Equador e parte acompanha o contorno da margem continental. Sugere-se que este anticiclone aumenta a energia do ambiente em estudo dificultando, desta forma, a deposição da matéria orgânica.

Marin (2009) verificou ainda que a SNB se intensifica à medida que se desloca para o norte, com aumento de seu transporte e velocidade. Entretanto, o posicionamento de seu núcleo torna-se cada vez mais raso, podendo justificar os valores mais altos encontrados no talude continental oeste do Ceará por Abreu Neto (2012). 


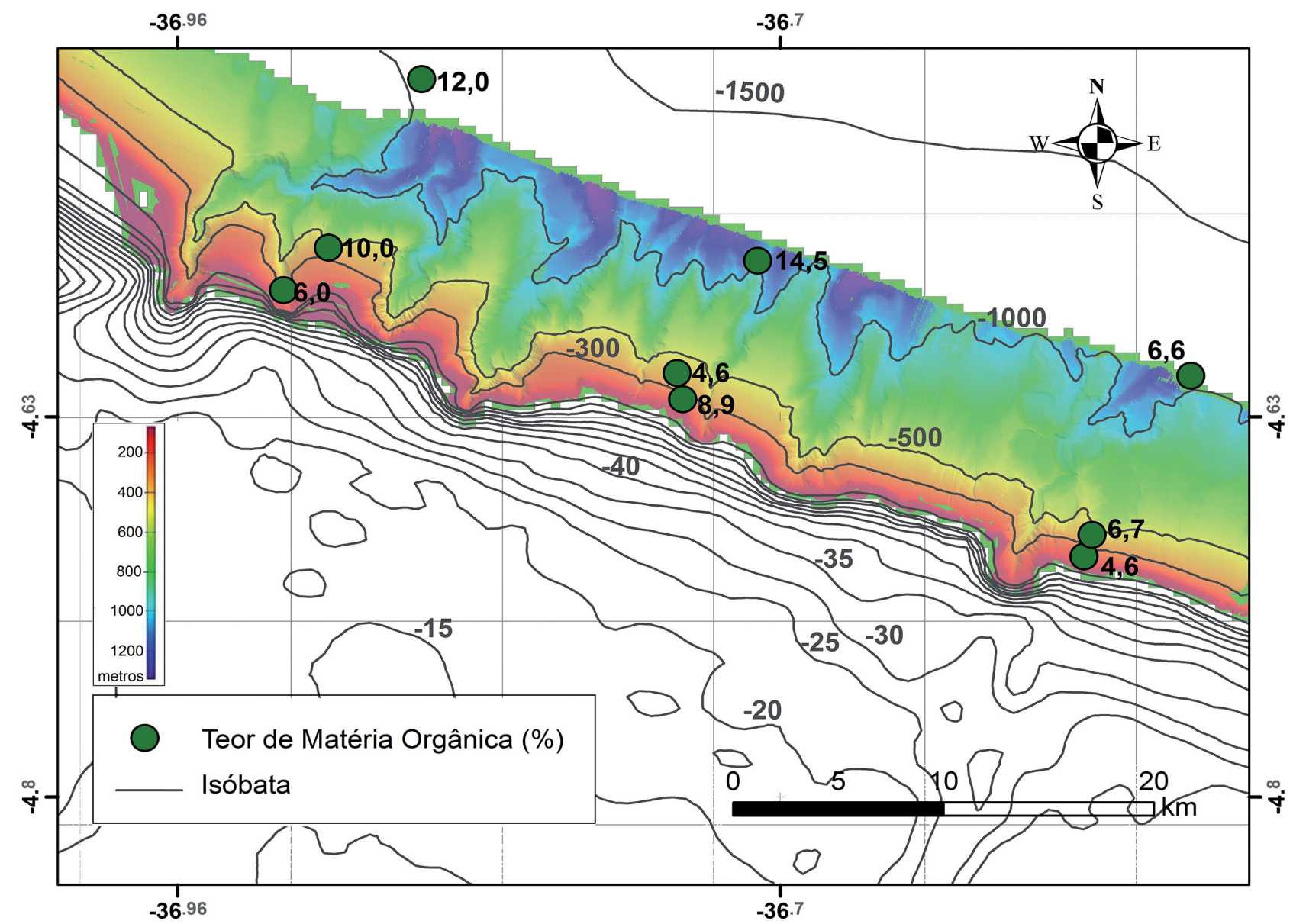

Figura 6. Distribuição do teor de matéria orgânica.

Figure 6. Distribution of organic matter content.

\subsection{Constituintes da sedimentação}

A sedimentação de ambientes profundos como taludes continentais pode ser constituída por diversos tipos de sedimentos, tais como os sedimentos siliciclásticos, bioclásticos, autigênicos, vulcanogênicos e cosmogênicos (d'Ávila et $a l ., 2008)$. Dois tipos de sedimentos foram identificados no talude do Rio Grande do Norte: os siliciclásticos e os bioclásticos, que diferem, sobretudo, quanto à composição e ao local de formação. Os siliciclásticos são alóctones, trazidos de fora do ambiente marinho, enquanto os bioclásticos são geralmente autóctones, formados no próprio ambiente, mas também podem ser transportados.

Os siliciclásticos podem ser sedimentos relíquias, ou seja, "areias remanescentes de ambiente anterior distinto do atual", conforme a definição de Emery (1952, 1968). Estes sedimentos relíquias foram depositados por processos continentais associados a canais fluviais e geleiras, durante eventos pretéritos de rebaixamento do nível do mar que ocorreram durante os períodos glaciais. Estes depósitos de nível de mar baixo podem ter sido parcialmente retrabalhados e afogados pelos diferentes eventos transgressivos que ocorreram durante o Quaternário, sendo então denominados de sedimentos "palimpsestos" (Swift et al., 1971).

\subsubsection{Siliciclásticos}

Os sedimentos siliciclásticos do talude continental da Bacia Potiguar são constituídos predominantemente por Quartzo, ocorrendo também Argilominerais como Ilita, Montmorillonita, Vermiculita, Clorita, Caulinita e Zeólita. Como acessórios aparecem Muscovita, Biotita e Glauconita, e os minerais pesados: Ilmenita, Zircão, Titanita, Estaurolita, Cordierita, Siderita, Rutilo, Magnetita, Turmalina, Pirita, Monazita e Barita (Tab. 2; fig. 8). Quartzo e Ilita estão presentes em todas as estações.

Esta composição reflete a constituição da área fonte e indica que os sedimentos foram trazidos do continente pelos rios, vales incisos, tendo sido dispersos no talude continental através dos canyons submarinos, marés e correntes oceânicas.

Os sedimentos mais grossos (areia com cascalho, areia siltosa e silte arenoso) ficaram retidos junto à região mais rasa da área de estudo, até a profundidade de $420 \mathrm{~m}$. Porém, correntes de turbidez foram capazes de transportar volumes de 
clásticos até dezenas de quilômetros da costa. Ainda nas estações mais profundas (N73, N74 e N75) foram encontrados sedimentos siliciclásticos, mesmo que em menores quantidades.

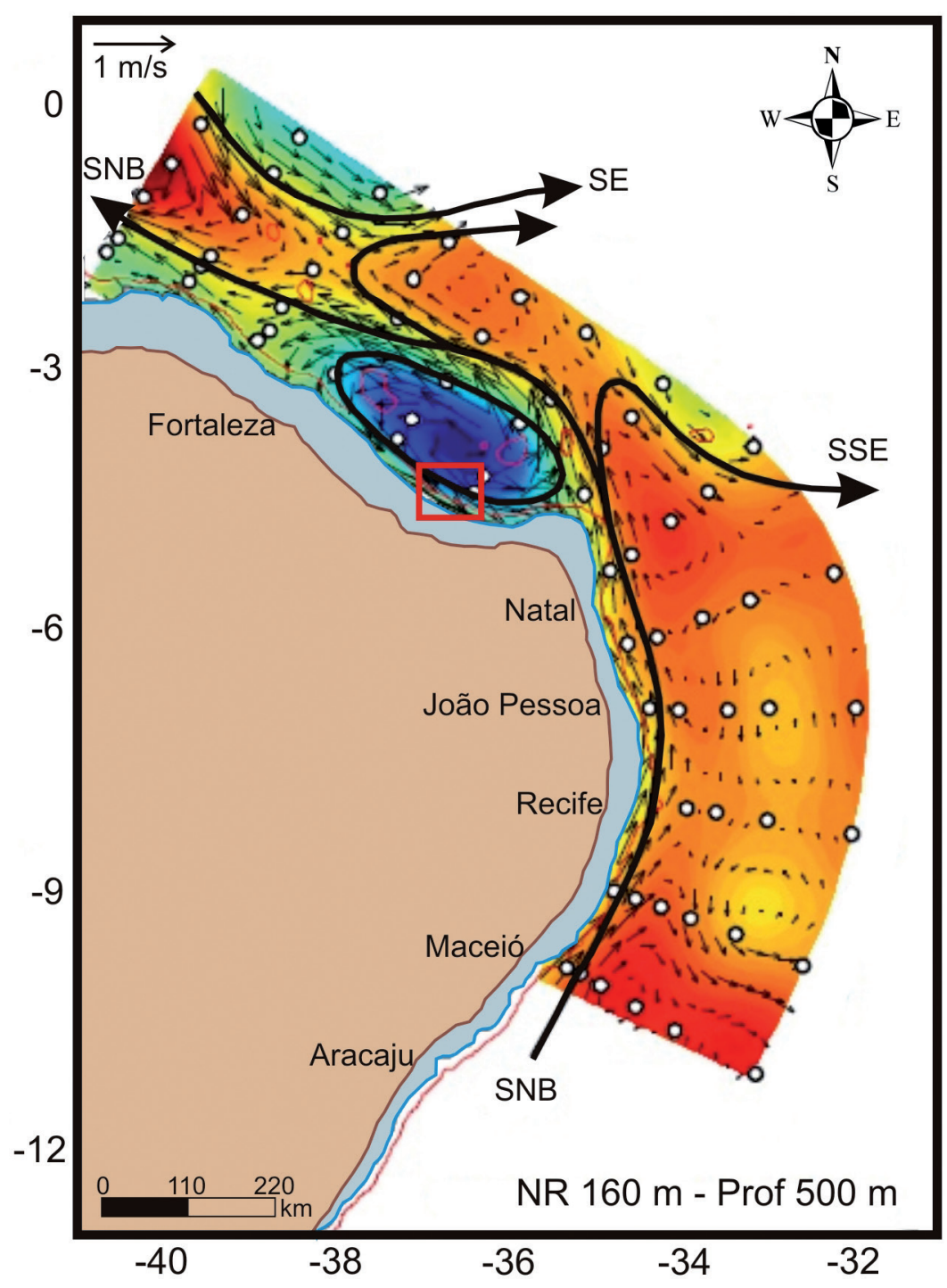

Figura 7. Mapa de função de corrente geostrófica absoluta. Vetores de velocidade geostrófica absoluta (m/s) sobrepostos aos campos de função de corrente geostrófica absoluta $\left(\mathrm{m}^{2} / \mathrm{s}\right.$ ) (Adaptado de Marin, 2009). Retângulo vermelho representa a área de estudo.

Figure 7. Map of absolute geostrophic current function. Absolute geostrophic velocity vectors $(\mathrm{m} / \mathrm{s}$ ) overlaid on absolute geostrophic current function fields ( $\mathrm{m}^{2} / \mathrm{s}$ ) (Adapted from Marin, 2009). Red rectangle is the study area.

A presença da Glauconita (filossilicato hidratado de potássio e ferro) e dos Argilominerais indica um ambiente marinho calmo e com baixas taxas de sedimentação. A Glauconita pode ser formada de modo autigênico nos sedimentos marinhos influenciada pela degradação da matéria orgânica e apresenta baixa resistência ao intemperismo; indica ambientes redutores (Hower \& Thompson, 1975; Lapido-Loureiro et al., 2009).

Os Argilominerais associados aos sedimentos de granulometria fina da área de estudo (silte, silte arenoso, areia siltosa) indicam que, no geral, a área compõe um ambiente de baixa energia que propicia a lenta deposição destes minerais.

Segundo Silva (1999) e Silva \& Vital (2000), ao longo do Rio Açu foram identificadas várias es- pécies de minerais pesados, tais como Turmalina, Estaurolita, Zircão, Rutilo e os opacos Ilmenita e Magnetita. A presença de minerais pesados estáveis, como Zircão, Turmalina e Rutilo, está associada às contribuições dos rios Açu e Apodi nos sedimentos marinhos profundos. Esse transporte ocorreu mais diretamente quando o nível do mar estava mais baixo que o atual, durante o Último Máximo Glacial, há aproximadamente 20.000 anos, quando esta plataforma continental ficou exposta e os rios a escavaram até aproximadamente $107 \mathrm{~m}$ (Peltier, 1998), alcançando a quebra da plataforma e o talude continental superior.

Além das mudanças do nível do mar, correntes e marés também são responsáveis pelo transporte e distribuição pretérita e atual dos sedimen- 
tos marinhos.

Estudos mais detalhados visando obter a concentração de cada mineral devem ser desenvolvidos, já que alguns minerais de interesse econômi- co foram encontrados, tais como Ilmenita, Zircão, Titanita, Estaurolita, Cordierita, Siderita, Rutilo, Magnetita, Turmalina, Pirita, Monazita e Barita.

Tabela 2. Compilação da mineralogia constituinte de cada estação de amostragem. (Montm. = Montmorilonita). Table 2. Mineralogy of sampling stations. (Montm. = Montmorillonite).

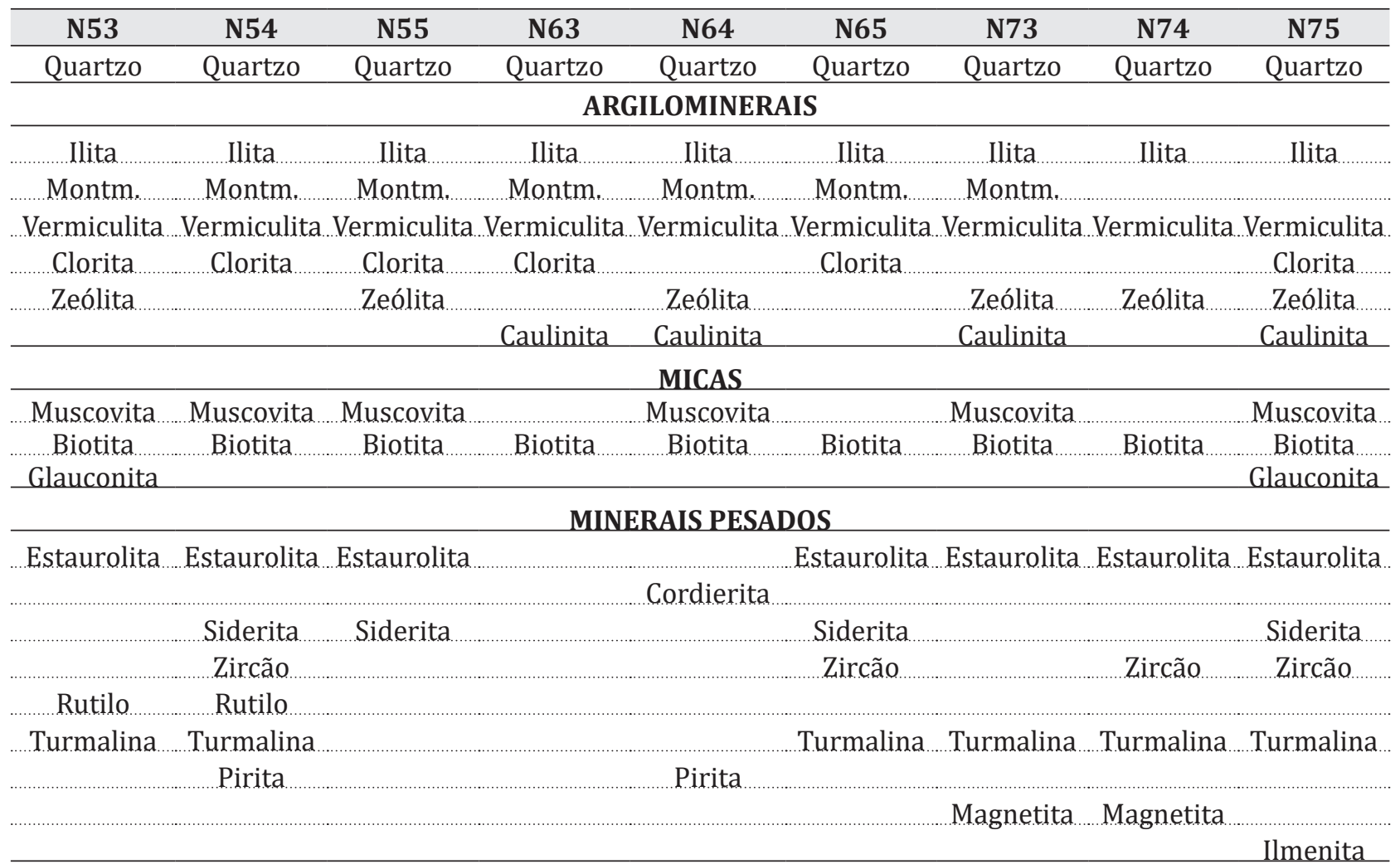

\subsubsection{Bioclásticos}

Os sedimentos bioclásticos do talude continental da Bacia Potiguar são formados principalmente pela acumulação de carapaças de microrganismos. Foram identificados diversos tipos de componentes biogênicos ou organismos, tais como: briozoários, esponjas e suas espículas, foraminíferos, anelídeos, nemátodas, moluscos e diatomáceas (Fig. 9).

De acordo com Ruppert \& Barnes (1996) e Távora (2000) os briozoários são animais coloniais, solitários, dominantemente marinhos e cosmopolitas, possuindo uma carapaça constituída por Calcita magnesiana e Aragonita. Suas estruturas morfológicas são calcárias ou quitinosas superficiais, sendo também conhecidas como esponjas, têm hábito bentônico séssil na fase adulta e são exclusivamente aquáticas. Estas podem ter espículas constituídas por carbonato de cálcio (Aragonita ou Calcita) ou por sílica. Na área de estudo predominam esponjas do gênero Conopeum incrustados em conchas e em hastes de Acropora em recifes de corais. Além de esponjas, foram também identificados foraminíferos, como por exemplo, os gê- neros Amphistegina (bentônicos) e Globigerina (planctônicos, Fig. 9B). A presença de foraminíferos do gênero Amphistegina reflete o transporte por fluxos de massa e/ou correntes de turbidez, de sedimento transportado da plataforma continental de regiões próximas de recifes de corais e esponjas. 0 gênero Globigerina presente nos mares indica geralmente ambiente de alta profundidade.

Moluscos das classes Gastropoda, Bivalvia e Scaphopoda foram identificados. As conchas dos moluscos são geralmente bem calcificadas, sendo composta por Aragonita ou Calcita. A classe Gastropoda corresponde ao maior grupo de moluscos e a concha é única sendo interna ou externa. $\mathrm{Na}$ classe Bivalvia a concha possui duas partes que encerram completamente o corpo do animal. $\mathrm{Na}$ classe Scaphopoda, os pequenos animais são dotados de uma concha cônica e alongada. Os tubos de vermes estão incluídos no filo dos anelídeos, onde os tipos encontrados nesta pesquisa foram os poliquetas pertencentes à classe Polychaeta.

Tendo em vista a importante contribuição biogênica aos sedimentos bioclásticos do talude da área de estudo, fatores como latitude, temperatura, salinidade, profundidade da água, intensi- 
dade da luz, turbidez, circulação oceânica, pressão de $\mathrm{CO}_{2}$ e suprimento sedimentar, atuam de forma conjunta, e possibilitaram condições necessárias para a proliferação desses organismos que juntamente com os sedimentos siliciclásticos perfazem os sedimentos do talude norte potiguar.
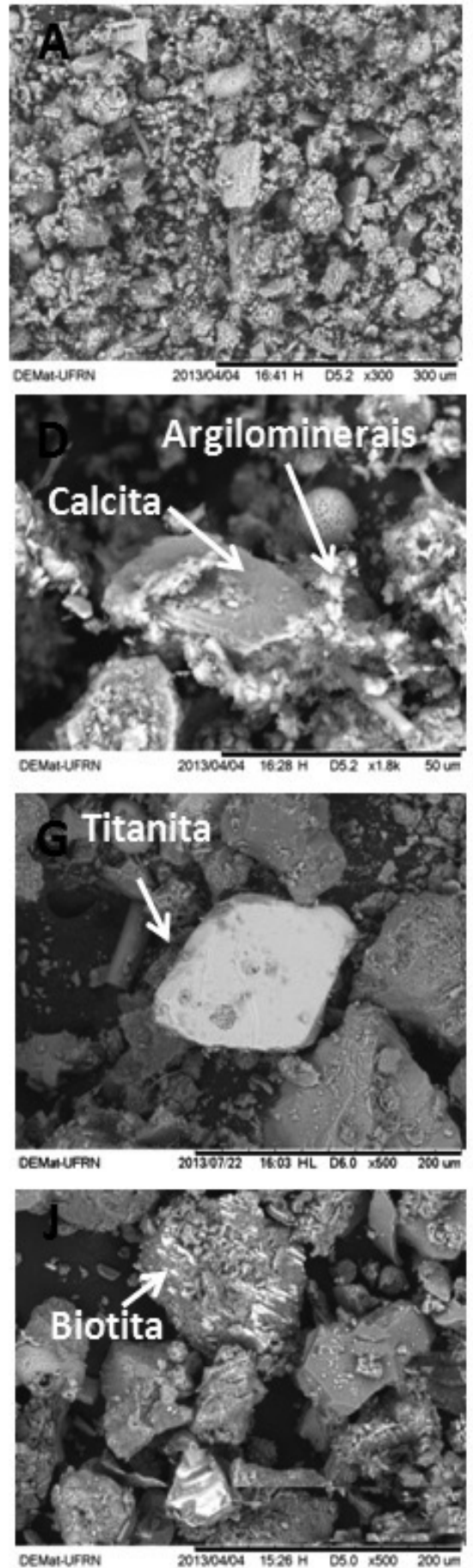

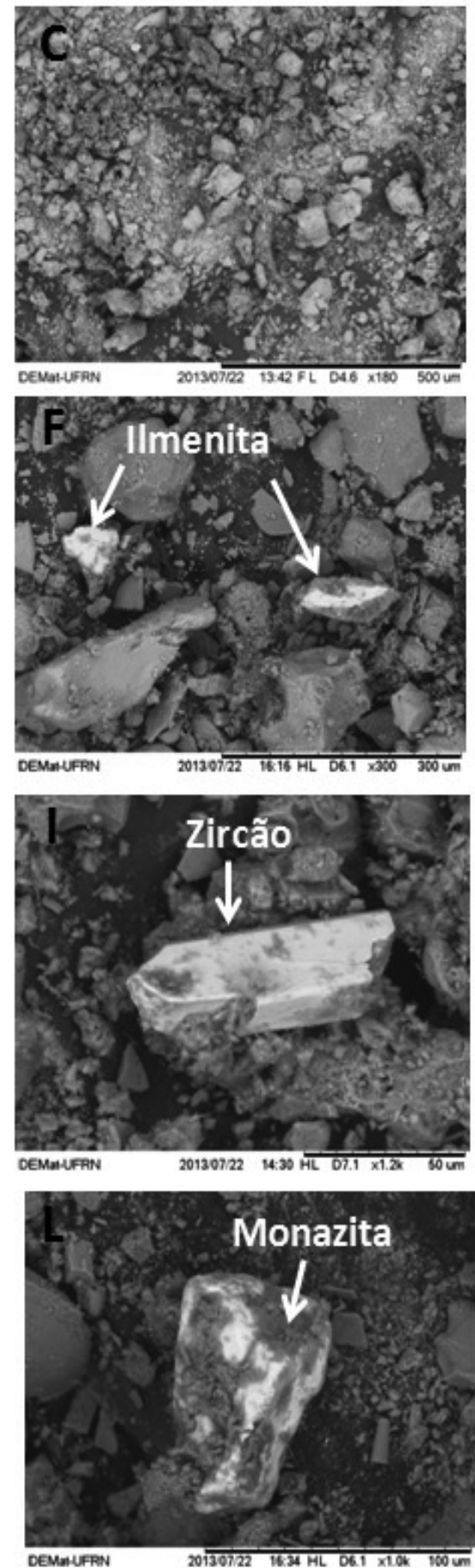

Figura 8. Imagens da microscopia eletrônica de varredura. A, B e C) Visões gerais das amostras; D) a L) Minerais constituintes dos sedimentos do talude norte potiguar, como Ilmenita, Titanita, Zircão, Biotita em fragmento de rocha, Barita e Monazita. Figure 8. Images of scanning electron microscopy. A, B and C) Overviews of the samples; D) to L) Minerals constituents of sediments of the northern continental slope of Rio Grande do Norte, such as, Ilmenite, Titanite, Zircon, Biotite in rock fragment, Barite and Monazite.

Entretanto, alguns sedimentos encontram-se fragmentados, apresentando um grau de retrabalhamento considerável (Figs. 8 e 9), decorrente da ação das correntes. Assim, esses sedimentos caracterizam-se como uma assembleia mista de sedimentos autóctones e alóctones possivelmente relacionados à CNB (Castro \& Miranda, 1996; Marin, 2009) e às correntes das paleodesembocaduras dos rios Apodi e Açu durante a última máxima transgressão (Almeida et al., 2015). 

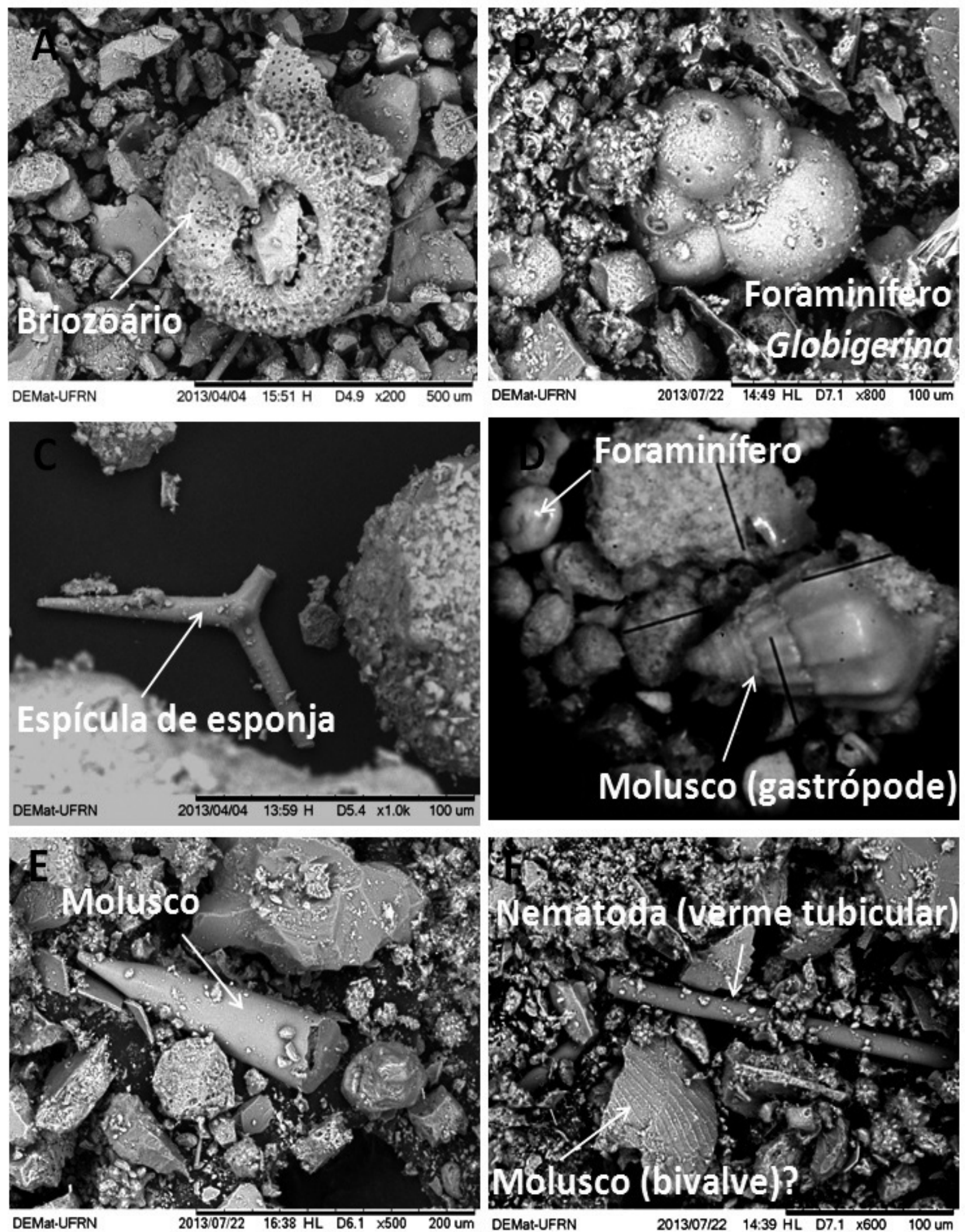

Figura 9. Imagens obtidas por microscopia eletrônica de varredura (A, B, C, E, F e G) e lupa binocular (D) de sedimentos bioclásticos do talude continental da Bacia Potiguar. A) Briozoário; B) Foraminífero Globigerina; C) Espícula de esponja; D) Molusco (gastrópode), aumento de 40x; E) Molusco; F) Nemátoda (verme tubicular) e Molusco.

Figure 9. Images obtained by scanning electron microscopy and binocular microscope. Bioclastic sediments of continental slope of the Potiguar Basin. A) Bryozoan; B) Foraminifera: Globigerina; C) Sponge spicule; D) Mollusc: Gastropod; E) Mollusc; F) Nematode (tubicular) and Mollusc. 


\section{Conclusões}

Os resultados deste estudo indicam um afinamento textural de sul para norte, onde em águas mais profundas $(\sim 1.000 \mathrm{~m})$, destaca-se a fácies silte que juntamente com a fácies silte arenosa perfazem $66 \%$ dos sedimentos estudados. Outras fácies como areia siltosa e areia com cascalho também foram encontradas. 0 teor de carbonato de cálcio é considerado moderado a alto (37 a 93,2\%) e o de matéria orgânica é baixo $(4,6$ a 14,5\%).

Os sedimentos presentes são siliciclásticos e bioclásticos. Dentre os siliciclásticos destacam-se Quartzo e os Argilominerais. A presença de alguns minerais pesados tais como Zircão, Turmalina e Rutilo indicam a maturidade dos sedimentos e a contribuição dos rios Açu e Apodi para o talude continental. Dentre os bioclásticos, destacam-se briozoários, esponjas, foraminíferos, anelídeos (tubos de poliquetas), nemátodas, moluscos (gastrópodes, bivalves e escafópodes) e diatomáceas. Encontram-se bastante fragmentados, evidenciando o retrabalhamento dos sedimentos pelas correntes.

Espera-se que estes resultados venham fornecer suporte a uma melhor compreensão sobre este ambiente deposicional moderno e subsidiar a melhoria contínua da gestão ambiental, uma vez que o conhecimento gerado deve ser usado para o desenvolvimento sustentável de atividades de exploração e produção petrolífera na região.

Sugere-se para trabalhos futuros, a seleção de áreas para o adensamento da amostragem, incluindo amostragem no interior dos canyons (Almeida et al., 2015), e um levantamento de dados de geofísica marinha, tais como de side scan sonar, que auxiliaria no reconhecimento de detalhe da sedimentação superficial da área.

Agradecimentos. Agradecimentos são devidos à PETROBRAS - PETRÓLEO BRASILEIRO S/A, pela cessão das amostras, no âmbito do Programa Monitoramento Ambiental Costeiro e Oceânico, Projeto de Caracterização Ambiental do Talude Continental na Bacia Potiguar; ao PRH-22/ANP (FINEP/CTPETRO/PETROBRAS) pela concessão de bolsa de mestrado à primeira autora; ao CNPq pela bolsa de pesquisa à H. Vital (311413 /20161) e a CAPES - Ciências do Mar 2 no. 43/2013 pela bolsa pós-doutoramento à $P$. Eichler (23038.004320/201411); à UFRN através da Pós-Graduação em Geodinâmica e Geofísica e dos Departamentos de Geologia, de Física e de Engenharia de Materiais pela infraestrutura necessária. Por fim, agradecemos a toda equipe do GGEMMA, pelo apoio durante o processamento dos dados. Este trabalho é uma contribuição do Projeto GeoImageamento (FINEP/DHN/SECIRM/PGGM/Marinha do Brasil) e Projeto Geohazards e Tectônica na Margem Equatorial Brasileira (IODP-CAPES).

\section{Referências}

Abreu Neto, J.C. 2012. Análise Textural e Geoquímica dos Argilominerais do Talude Continental do Oeste do Ceará. Fortaleza, 77p. Dissertação de Mestrado. Programa de Pós-Graduação em Geologia, Universidade Federal do Ceará.

Almeida, N.M., Vital, H. \& Gomes, M. P. 2015. Morphology of submarine canyons along the continental margin of the Potiguar Basin, NE Brazil. Marine and Petroleum Geology, 68: 307-324.

Borges, M.E.P. 2012. Caracterização sedimentológica do vale inciso Apodi-Mossoró, Bacia Potiguar - offshore. Natal, 60p. Monografia de Conclusão de Curso, Departamento de Geologia, Universidade Federal do Rio Grande do Norte.

Castro, B.M. \& Miranda, L.B. 1996. Physical oceanography of the western Atlantic continental shelf located between $4^{\circ} \mathrm{N}$ and $34^{\circ} \mathrm{S}$. The Sea, 11 (8): 209-251.

Cunha, E.M.S. 1982. Caracterização e Planejamento Ambiental do Estuário Potengi. Natal, 211p. Dissertação de Mestrado, Departamento de Oceanografia e Limminologia, Universidade Federal do Rio Grande do Norte.

d'Ávila, R.S.F., Arienti, L.M., Aragão, M.A.N., Vesely, F.F., Santos, S.F., Voelcker, H.E., Viana, A.R., Kowsmann, R.O., Moreira, J.L.P., Coura, A.P.P., Paim, P.S.G., Matos, R.S. \& Machado, L.C.R. 2008. Ambientes Marinhos Profundos: Sistemas turbidíticos. In: Silva, A.J.P., Aragão, M.A.N.F. \& Magalhães, A.J.C. (Eds.). Ambientes de sedimentação siliciclástica do Brasil. São Paulo, Beca, p. 244-301.

Dias, G.T.M. 1996. Classificação de sedimentos marinhos, proposta de representação em cartas sedimentológicas. In: CONGRESSO BRASILEIRO DE GEOLOGIA, 39: Salvador. Anais... Salvador: SBG, 1996, 3: 423-426.

Dias, G.T.M. \& Ferraz, C.B. 2004. SAG - Sistema de Análise Granulométrica. Manual do usuário. Departamento de Geologia, Laboratório de Geologia Marinha, Universidade Federal Fluminense.

Emery, K.O. 1952. Continental Shelf sediments of Southern California. Geological Society of America Bulletin, 63 (11): 1105-1108.

Emery, K.O. 1965. Characteristics of Continental Shelves and Slopes. American Association of Petroleum Geologists Bulletin, 49: 1379-1384.

Emery, K.O. 1968. Relict sediments on continental shelves of the world. American Association of Petroleum Geologists Bulletin, 52 (3): 445-464.

Erickson, J. 2003. Marine geology: exploring the new frontiers of the ocean. New York, The living earth (Rev.ed.), 317p.

Fairbridge, R.W. 1966. Encyclopedia of Geomorphology. New York, Reinhold Book, 1021p.

Folk, R.L. 1954. The distinction between grain size and mineral composition in sedimentary rock nomen- 
clature. Journal of Geology, 62(4): 344-359.

Folk, R.L. 1974. The natural history of crystalline calcium carbonate: Effect of magnesium content and salinity. Journal of Sedimentary Petrology, 44: 40-53.

Freire, G.S.S., Cavalcanti, V.M.M., Maia, L.P. \& Lima, S.F. 1997. Classificação dos Sedimentos da Plataforma Continental do Estado do Ceará. In: SIMPÓSIO DE GEOLOGIA DO NORDESTE. Anais... , Fortaleza, CE, p. 209-211.

Gomes, M. P. \& Vital, H. 2010. Revisão da Compartimentação Geomorfológica da Plataforma Continental Norte do Rio Grande do Norte. Revista Brasileira de Geociências, 40(3): 321-329.

Harrell, J.A. 1984. A visual comparator for degree of sorting in thin and plane sections: Journal of Sedimentary Petrology, 54: 646-650.

Hower, J. \& Thompson, G.R. 1975. The mineralogy of Glauconite. Clays and Clay Minerals, 23: 289-300.

Inman, D.L. 1952. Measures for describing the size distribution of sediments. Journal of Sedimentary and Petrology, 22(3): 125-145.

Lapido-Loureiro, F.E., Nascimento, M., Neumann, R. \& Rizzo, A.C. 2009. Tecnologias de Aplicação de Glauconita como Fonte de Potássio na Agricultura: O Caso Brasileiro e a Experiência Indiana. In: CONGRESSO BRASILEIRO DE ROCHAGEM, 1, Anais... Brasília, DF.

Larsonneur, C. 1977. La cartographie des depot meubles sur le plateau continental francais: methode mise au point et utilisee en manche. Journal de Recherche Oceanographique, 2: 34-39.

Lima, S.F. \& Vital, H. 2006. Geomorphological and paleogeographic characterization of continental shelf of the Apodi-Mossoró River, RN-Brazil. In: Brebbia, C.A. (ed.). Enviromental problems in coastal regions VI: Including oil spill studies. Wessex Institut of technology, Cambridge printing, p. 351-360.

Loring, D.H. \& Rantala, R.T.T. 1992. Manual for the geochemical analysis of marine sediments and suspended particulate matter. Earth-Sciences Reviews. 32: 235-283.

Marin, F.O. 2009. A Subcorrente Norte do Brasil ao largo da Costa do Nordeste. São Paulo, 115 pp. Dissertação de Mestrado, Instituto Oceanográfico, Universidade de São Paulo.

Mayer, D.A. \& Weisberg, R.H. 1993. A description of COADS surface meteorological fields and the implied Sverdrup transport for the Atlantic Ocean from $30^{\circ}$ $\mathrm{S}$ to $60^{\circ} \mathrm{N}$. Journal of Physical Oceanography, 23: 2201-2221.

Meyers, P.A. \& Lallier-Vergés, E.L. 1999. Lacustrine sedimentary organic matter records of Late Quaternary paleoclimates. Journal of Paleolimnology, 21(3): 345-372.

McCave, I.N. \& Syvitski, J.P.M. 1991. Principles and methods of particle size analysis. In: Syvitski, J.P.M. (Ed.). Principles, Methods, and Applications of Particle Size Analysis. New York, Cambridge University Press, p. 3-21.

Moreira, J.P.L. \& Carminatti, M. 2004. Sistemas deposicionais do talude e de bacia no Eoceno da Bacia de Santos. Boletim de Geociências da Petrobras, 12 (1):
73-87.

Palma, J.J.C. 1984. Fisiografia da área oceânica. In: Schobbenhaus, C., Campos, D.A., Derze, G.R. \& Asmus, H.E. (Ed.). Geologia do Brasil. Brasília, MME/DNPM, p. 429-441.

Peltier, W.R. 1998. Global glacial isostatic adjustment and coastal tectonics. In: Stewart, I. \& Vita-Finzi, C. (Ed.). Coastal Tectonics. London, Geological Society, p. 1-29.

Pessoa Neto, 0.C. 2003. Estratigrafia de sequencia da plataforma mista neogênica na Bacia Potiguar, Margem Equatorial Brasileira. Revista Brasileira de Geociências, 33: 263-278.

Ruppert, E. E. \& Barnes, R.D. 1996. Zoologia dos Invertebrados. São Paulo, Editora Roca, 1029p.

Schott, F.A., Fischer, J. \& Stramma, L. 1998. Transport and pathways of the Upper-layer circulation in the Western Tropical Atlantic. Journal of Physical Oceanography, 28: 1904-1928.

Schwab, A. M., Trenblay, S. \& Hurst, A. 2007. Seismic expression of turbidity-current and bottom-current processes on the Northern Mauritanian continental slope. In: Davies, R.J., Posamentier, H.W., Wood, L. J. \& Cartwright, J.A. (Ed.) Seismic Geomorphology: Applications to Hydrocarbon Exploration and Production. London, Geological Society, p. 237-252.

Schwarzer, K., Stattegger, K., Vital, H. \& Becker, M. 2006. Holocene coastal evolution of the Rio Açu area (Rio Grande do Norte, Brazil). Journal of Coastal Research, SI 39: 141-145.

Shepard, F.P. 1954. Nomenclature based on sand-silt-clay ratios. Journal of Sedimentary Petrology, 24: 151-158.

Silva, M.G. 1999. Caracterização dos Minerais Pesados ao Longo do Rio Piranhas-Açu/RN: Distribuição e Proveniência. Natal, 71 pp. Dissertação de Mestrado, Programa de Pós Graduação em Geodinâmica e Geofísica, Universidade Federal do Rio Grande do Norte.

Silva, M.G. \& Vital, H. 2000. Provenance of heave-minerals in the Piranhas-Açu Rivers, NE Brazil. Revista Brasileira de Geociências, 30(3): 449-452.

Silveira, I.C.A., Miranda, L.B. \& Brown, W.S. 1994. On the origins of the North Brazil Current. Journal of Geophysical Research, 99(11): 501-512.

Stoker, M.S., Evans, D. \& Cramp, A. 1998. Geological processes on continental margins: Sedimentation, Mass-wasting and Stability. London, Geological Society, 129p.

Swift, D.J.P., Stanley, D.J. \& Curray, J.R. 1971. Relict sediments on continental shelves: a

reconsideration. Journal of Geology, 79 (3): 322-346.

Távora, V.A. 2000. Briozoários. In: Carvalho, I.S. (Ed.). Paleontologia. Rio de Janeiro, Interciência, p. 329350.

Testa, V. \& Bosence, D.W.J. 1998. Carbonate-siliciclastic sedimentation on highenergy, ocean-facing, tropical ramp, NE Brazil. In: Wright, V.P. \& Burchette, T.P. (Ed.). Carbonate Ramps. London, Geological Society, p. 55-71.

Vital, H., Stattegger, K., Amaro, V.E., Schwarzer, K., Frazão, E.P., Tabosa, W.F. \& Silveira, I.M. 2008. A modern 
high-energy siliciclastic-carbonate platform: Continental shelf adjacent to northern Rio Grande do Norte State, Northeastern Brazil. In: Hampson, G. \& Dalrymple, R. (Eds.). Recent advances in models of siliciclastic shallow-marine stratigraphy. Tulsa, Society for Sedimentary Geology, p. 175-188.

Vital, H., Gomes, M.P., Tabosa, W.F., Frazao, E.P., Santos, C.L.A. \& Placido Junior, J.S. 2010a. Characterization

\section{Manuscrito 625}

Editores: Eduardo G. Barboza \& Maria do Carmo Lima e Cunha of The Brazilian Continental Shelf Adjacent to Rio Grande do Norte State, NE Brazil. Brazilian Journal of Oceanography, 58(SI): 43-54.

Vital, H., Furtado, S.F.L. \& Gomes, M.P. 2010b. Response of Apodi-Mossoro Estuary-Incised Valley System (NE Brazil) to Sea-Level Fluctuations. Brazilian Journal of Oceanography, 58: 13-24. 
